\title{
Binmore, Ken. 2000. GAME THEORY AND The Social Contract. Volume 1 Playing Fair. The MIT Press, 359 Pp.
}

Contractualismo y teoría de juegos pueden ser a simple vista áreas disciplinarias demasiado diferentes como para merecer un libro 0 , cuando menos, el público interesado en ambas materias pareciera no ser abundante. Sin embargo, las dos impresiones son bastante erradas en la medida en que a partir de Rawls ${ }^{1}$ el impacto de las concepciones morales sobre la organización social y la distribución de los beneficios de la misma cobró singular importancia. Binmore, al igual que Buchanan y Brennan ${ }^{2}$-autores que inspirados por la obra de Rawls pretenden llevar la idea de un contrato social que refleje las convicciones morales más profundas relacionadas a la libertad y la igualdadtambién presenta sus objeciones a la obra de Rawls.

Si bien el libro no resulta ser precisamente nuevo, hay más de una razón que permiten destacarlo. La primera es que es más apropiado referirse al volumen 1 teniéndolo en perspectiva tras haber podido revisar el volumen 2, publicado algún tiempo después. La segunda es su enorme valor analítico, a pesar del escaso impacto que parece tener en los países de habla hispana. La tercera es que el autor es una autoridad en teoría de juegos del University College London, con varias publicaciones sobre la materia ${ }^{3}$, desde donde como matemático comenzó a explorar la economía y luego la teoría política. Y la cuarta, es que el nivel de atemporalidad de los contenidos hacen del libro un escrito menos susceptible a la obsolescencia.

Game Theory and The Social Contract. Volume 1 Playing Fair ciertamente no es un buen punto de partida ni para estudiar teoría y filosofía política, ni para iniciarse en la teoría de juegos. Pero ello no implica que sea necesario dominar cabalmente ambas o ser un experto de ambas áreas. Muy por el contrario, para quien ya está familiarizado con algunos de los autores, entre ellos Hobbes, Hume, Locke, Rousseau, Kant, Bentham, Mill y Harsanyi o el propio Rawls, podrá introducirse y llegar a interesarse por la teoría de juegos; mientras que quien se aproxime al tema desde la teoría de juegos podrá sacar partido de las categorías analíticas que distinguen el comportamiento humano y que le dan contenido a la teoría formal, ya que como el propio autor señala: “... this book presents mathematical arguments in a navie style becouse they are never genuinely important. What matters are always interpretative questions"4.

J. Rawls. A Theory of Justice. Oxford: Oxford Universty Press, 1972.

Brennan, Geoffrey \& Buchanan, James M. 1985. The Reason of Rules. Constitutional Political Economy. Cambridge: Cambridge Universty Press.

3 Entre ellas: Economic Organizations as Games, The Economics of Bargaining, Essays on the Foundations of Game Theory y Fun and Games.

4 Binmore, Ken. 2000. Game Theory and The Social Contract. Volume 1 Playing Fair. The MIT Press, pág. 85. (Itálicas en el original). 
Uno de los conceptos más interesantes que el autor introduce es del "game of morals" ${ }^{5}$ en contraste con el de "game of life"6. Mientras el primero se refiere a los posibles resultados de la interacción entre las capacidades de los diversos agentes que interactúan en el mundo real, el segundo apunta a una versión más compleja que involucra, además, las reglas morales que de uno u otro modo restringen el accionar de esos agentes reduciendo su abanico de posibilidades. Nótese que en el enunciado anterior la introducción de reglas morales no abre nuevas posibilidades, por el simple hecho de que ellas no son capaces de crear algo más allá de la frontera de Pareto. Binmore enfatiza varias veces ese punto, y sugiere que el debate entre socialistas de ala izquierda y conservadores no es una cuestión de redistribución, puesto que los primeros son los que ponen este punto como central, y los segundos están más atentos a cuánto es posible distribuir?

Sin embargo, mucho más revelador del pensamiento del autor es el concepto de "empatía" frente al de "simpatía" y otros"; que no es otra cosa que la capacidad ya no sólo de sentir lo que otros sienten, sino de comportarse de forma más o menos consistente en orden a intentar tomar en consideración las preferencias de esos otros. Para ello apela a lo que él llama un "velo delgado de la ignorancia"9 que constituye el fundamento de su contrato social, para cuya construcción emplea tres elementos: "restricciones a la información", que constituyen solamente la ignorancia, por parte de los suscriptores de ese contrato, de quién ocupará qué lugar en la sociedad, pero no sus propias preferencias ni conocimientos, los cuales son necesarios para construir el segundo elemento; los "contratos socialmente posibles", aludiendo a su idea de que el contrato social resultante no sólo debe ser posible en términos físicos, sino también debe considerar el hecho de que éste no debe ser independiente de quién termine ocupando qué rol en la sociedad (la aparente contradicción con el elemento anterior requiere una explicación más larga); y, finalmente, el "proceso de negociación", punto que, no obstante, no alcanza a ser tratado en en su totalidad y queda pendiente para el volumen $2^{10}$.

Sebastián Briones Instituto de Ciencia Política Pontificia Universidad Católica de Chile

Binmore, Ibidem, pág. 25.

Este concepto, junto con de Game of morals, permanece en el inglés original por cuanto su traducción puede ser muy equívoca y entre "el juego de la vida", "juego de vida" y otro posibles puede haber gran diferencia de matices. Ello se acentúa aún más en el caso del Game of morals, donde el plural del último término abre espacio para aún más ambigüedades en la traducción.

Binmore, lbídem, pág. 6

8 Entre esos otros cabe destacar el de los gemelos o "paradox of the twins", que alude básicamente a la idea de que personas diferentes pueden tener pensamientos similares, y por tanto comportarse de manera similar. El concepto es mucho más amplio que eso, pero el autor lo trata en su debida complejidad.

$9 \quad$ Binmore, Ibídem, pág. 327. En obvia y directa alusión al concepto de Veil of ignorance de Rawls.

10 Game Theory and the Social Contract. Volume 2: Just Playing. 2000. The MIT Press, 598 pp. 